\title{
Successful renal artery reconstruction using a polytetrafluoroethylene graft in living donor kidney transplantation: a case report
}

\author{
Suh Min Kim
}

Department of Surgery, Chung-Ang University Hospital, Seoul, Korea

Background: Arterial injury can occur during donor nephrectomy. Here, we report a case of successful reconstruction of damaged renal artery with a polytetrafluoroethylene (PTFE) graft in living donor kidney transplantation.

Case report: A 47-year-old female patient was admitted for kidney transplantation. She was diagnosed with chronic kidney disease due to immunoglobulin A nephropathy. The donor was her 23-year-old son and his left kidney was selected for allograft. Preoperative computed tomography angiography showed two left renal arteries including an upper pole accessory artery. During laparoscopic donor nephrectomy, inadvertent arterial injury occurred. The main renal artery was clamped and cut in the renal hilum. After removal of the clamp, two divided branches of main renal artery were shown. Both of the main and accessory renal arteries were too short to anastomose. A standard wall $4 \mathrm{~mm}$ PTFE graft was used for renal arterial reconstruction. Initially conjoined anastomosis of the two branches of the main renal artery was done and it was extended with a PTFE graft. Then end-toside anastomosis of the accessory renal artery to the PTFE graft was done. Finally, the end of the PTFE graft was anastomosed to the recipient's right internal iliac artery. The allograft was well perfused. The cold and warm ischemic times were 149 and 45 minutes, respectively. She underwent hemodialysis due to oliguria on postoperative day 3 . The urine output increased on postoperative day 5. Doppler ultrasonography on postoperative day 5 and 19 showed patent renal artery and well-perfused allograft. Renal function gradually improved and maintained with a serum creatinine level of $0.8 \mathrm{mg} / \mathrm{dL}$. She has been followed up with aspirin for 9 months without vascular complications.

Conclusions: Arterial reconstruction using a PTFE graft is acceptable for a damaged short renal artery of allograft. Follow-up with Doppler ultrasonography and adequate antiplatelet therapy was necessary.

Corresponding author: Suh Min Kim

E-mail: smkim819@hanmail.net

(c) The Korean Society for Transplantation

This is an Open Access article distributed under the terms of the Creative Commons Attribution Non-Commercial License (http://creativecommons.org/licenses/by-nc/4.0/) which permits unrestricted non-commercial use, distribution, and reproduction in any medium, provided the original work is properly cited. 